\title{
A FORMA PSEUDOMIOPÁTICA TARDIA DA ATROFIA MUSCULAR PROGRESSIVA HEREDO-FAMILIAL
}

\author{
Nunjo Finkel*
}

Com os trabalhos de WohIfart e col. ${ }^{25}$ e de Kugelberg e Welander 9 , a atrofia muscular de localização proximal heredo-familial de origem neurogênica ganhou foros de entidade autônoma. A síndrome relatada por êstes autores consiste, bàsicamente, em: 1) diminuição da fôrça muscular, iniciada na infância ou adolescência; 2) atrofia muscular de predomínio proximal; 3) hiporreflexia ou arreflexia muscular; 4) evolução extremamente lenta; 5) transmissão hereditária do tipo recessivo, não ligada ao sexo; 6) gênese neurogênica verificada mediante biopsia muscular e/ou eletromiografia; 7) presença de fasciculações na quase totalidade dos casos. Todos os pacientes apresentados tinham ascendência sueca.

Magee e DeJong ${ }^{12}$ reportaram 3 casos em família de origem alemã, todos porém nascidos na América do Norte, com modalidade de atrofia muscular semelhante àquela descrita na Suécia, diferindo em alguns aspectos (transmissão hereditária aparentemente do tipo dominante simples, ausência de progressão da enfermidade, reflexos profundos normais). Assinalam êstes autores que a atrofia muscular proximal hereditária é pouco freqüente e que, sem o auxílio da biopsia e da eletromiografia, poderá ser incorretamente diagnosticada como distrofia muscular progressiva. $\mathrm{Na}$ realidade os membros da família reportada por Magee e DeJong haviam sido originàriamente rotulados como portadores de distrofia muscular progressiva; a localização proximal e simétrica assim como a ausência de fasciculações conduziram inicialmente ao diagnóstico de atrofia miogênica, tendo a biopsia muscular excluído esta possibilidade.

Constitui ponto pacífico, desde os trabalhos clássicos de Erb, que as atrofias miogênicas não apresentam fasciculações. Curschmann, em 1936, dera ênfase a êste aspecto ao afirmar jamais ter assinalado a presença de fasciculações na distrofia muscular progressiva. Não obstante, conforme rerefere Wohlfart ${ }^{24}$, a literatura consigna exemplos de miopatias em que foram observadas fasciculações (Veiga de Sousa, 1888; Spilmann e Haushalter, 1890; Leri, 1901; Dejérine e Thomas, 1904). Spiller ${ }^{24}$ também menciona a ocorrência de fasciculações na distrofia muscular progressiva. Outros autores, particularmente do século passado, tais como Zimmerlin (1883),

* Da Clínica Neurológica do Hospital dos Servidores do Estado (Rio de Janeiro, Guanabara). 
Hitzig (1888) e Oppenheimer (1888), todos citados por Wohlfart ${ }^{24}$, reportam fasciculações como integrantes do quadro clínico de distrofia muscular progressiva. As observaçōes dêstes autores, como refere Wohlfart, foram objeto de críticas severas por parte de Erb, que mencionou um caso de distrofia muscular progressiva que tivera oportunidade de estudar, jamais tendo surpreendido fasciculações, caso êste que fôra relatado anteriormente por Penzoldt (1886) e por Stintzing (1889), ambos assinalando a presença de fasciculaçōes.

No diagnóstico diferencial das atrofias musculares, no que diz respeito à origem miogênica ou neurogênica, a presença de fasciculaçōes constitui evidência definitiva e incontestável de lesão do neurônio motor periférico. Fundamentados neste critério clínico, catalogamos os casos relatados a seguir como atrofias muzculares neurogênicas.

\section{OBSERVAÇÕES}

CASo 1 - A.A.M. (IVF8 no heredograma), 46 anos, branco, brasileiro (natural de Guarani, Minas Gerais), casado, examinado em 24-12-1957. História da doença atual - Relata o paciente que em meados de 1955 (isto é, aos 44 anos de idade) notou diminuição de fôrça do membro inferior direito, com fatigabilidade fácil e tropeços constantes, sendo que, para passar da posição sentada para a ereta, apoiava-se no membro inferior esquerdo. Em maio de 1957, o exame radiográfico da coluna vertebral revelou "escoliose torácica alta"; a punção lombar forneceu liquor

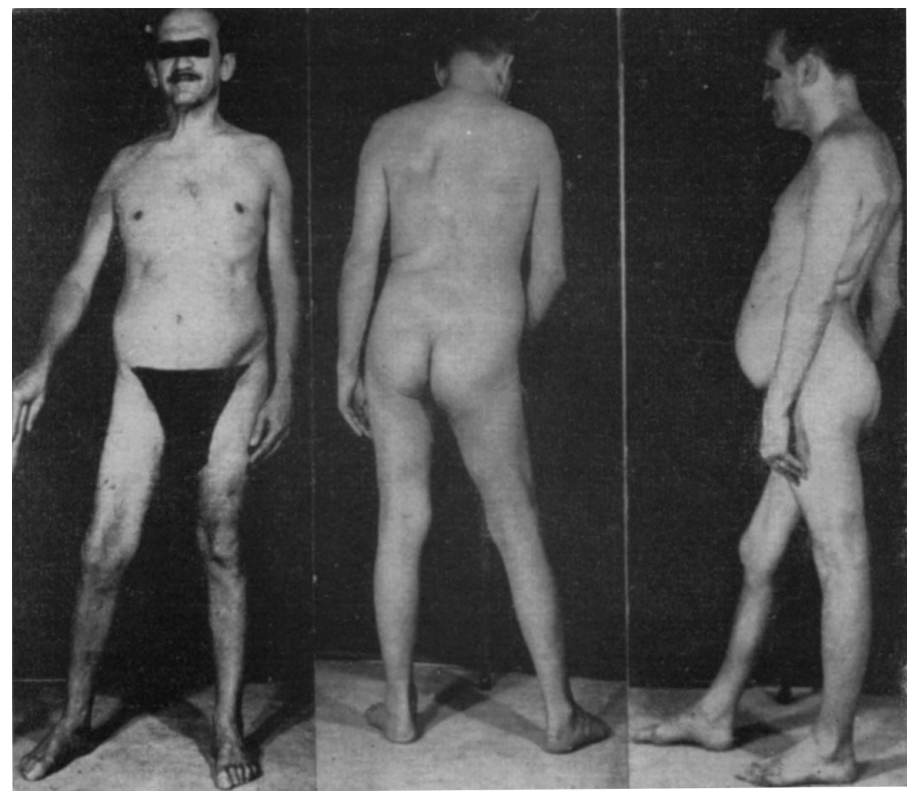

Fig. 1 - Caso 1, paciente IVF8: atrofia pelvifemoral e escápulouneral. 
normal. A partir de agôsto de 1957, notou diminuiçāo do volume muscular da região femoral direita. Em dezembro de 1957 teve "sensação de pêso" no membro inferior esquerdo, acompanhada de diminuição de fôrça. Todos os sintomas acima têm tido caráter progressivo. Nega distúrbios esfinctéricos. Antecedentes pessoais - Parto eutócico, gestação a têrmo. Doenças peculiares à primeira infância isentas de complicações. Nega passado venéreo. A idade de 16 anos, edema em tôda a extensão do membro inferior direito, quando foi verificada albuminúria, tudo desaparecendo após algumas semanas.
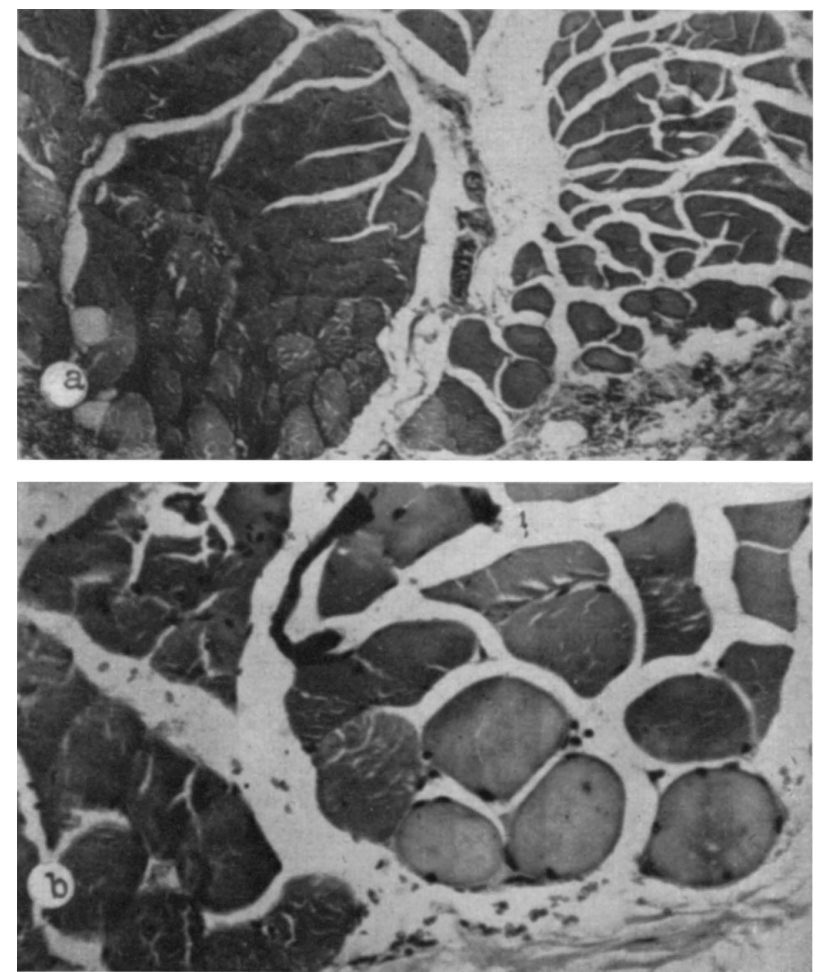

Fig. 2 - Caso 1, paciente IVF8. Biopsia muscular: em a, grupamentos musculares de arquitetura normal à esquerda $e$ atrofiados à direita; em b, fibras musculares cle citoplasma homogêneo, de permeio com fibras de estrutura normal (H.E. $100 \times$ e $240 \times$ ).

Exame neurológico - Nervos cranianos sem alteraçōes. Marcha claudicante com o membro inferior direito. Estática normal. Pronunciada lordose dorso-lombar. Abdome protuberante, particularmente a expensas do hipogástrio. Atrofia proximal do membro inferior direito (fig. 1). Ausência de hipertrofias ou pseudo-hipertrofias. Diminuição da fôrça de flexão da coxa direita sôbre a bacia. Quando deitado em decúbito dorsal, não passa para a posição sentada, sem auxílio dos membros superiores. Levantar miopático. Provas dedo-nariz e calcanhar-joelino normais. Reflexos musculares presentes e simétricos, com exceção dos aquileus, ambos abolidos. Reflexos plantares em flexão. Ausência de fasciculações. Sensibilidades superficial, profunda e discriminativa intatas. Psiquismo e linguagem normais. 
Exames complementares - Dosagem de transaminases: transaminase glutâmica (SGO-T) (Cabaud-Leeper-Wróblewski) 20 unidades; transaminase pirúvica (SGP-T) (Cabaud-Leeper-Wróblewski) 60 unidades. Biopsia muscular (material das regiões femoral anterior direita, tibial posterior direita e infra-espinhosa direita): "Tecido muscular esquelético, cortado em vários sentidos, predominando os cortes transversais; $2 / 3$ dos grupos musculares se apresentam com arquitetura preservada, enquanto que no têrço restante as fibras se apresentam com diâmetro reduzido, havendo aumento relativo do tecido intersticial e da celularidade; os grupos musculares apresentam-se individualizados por tecido fibroadiposo do perimisio que, nas porçóes periféricas do corte, exibe áreas de sufusāo hemorrágica; algumas fibras mostram estrutura normal, outras são tumefeitas e com citoplasma finamente vacuolado; algumas fibras revelam citoplasma com pouca afinidade corante, ou então densamente eosinófilo, de aspecto hialino, sem esbôço de estriaçāo (fig. 2). Não foram encontrados infiltrados inflamatórios e as estruturas vásculo-nervosas nāo exibem anormalidades" (Dr. Domingos de Paola).

Em 9 de novembro de 1960: Eletrocardiograma normal. O exame físico mostra atrofia pronunciada dos músculos da cintura escápulo-umeral e pelvifemoral, particularmente dos peitorais, trapézios, tríceps grandes glúteos e quadriceps. Diminuição da fôrça muscular de predominio proximal. Fasciculaçōes difusas, mormente nos músculos atrofiados. Tremor distal dos membros superiores na posição de juramento. Scapula alatae. Reflexos musculares presentes e simétricos, com exceção dos aquileus, abolidos. Reflexos plantares em flexão.

CASo 2 - E.D.M. (IIIR12 no heredograma), 49 anos, branca, brasileira (natural de Guarani, Minas Gerais), solteira, examinada em 9-9-1960. História da doença atual - Relata a paciente que aos 20 anos de idade teve "hipertireoidismo", tendo feito uso de várias medicações até a idade de 32 anos, quando foi submetida a ti-

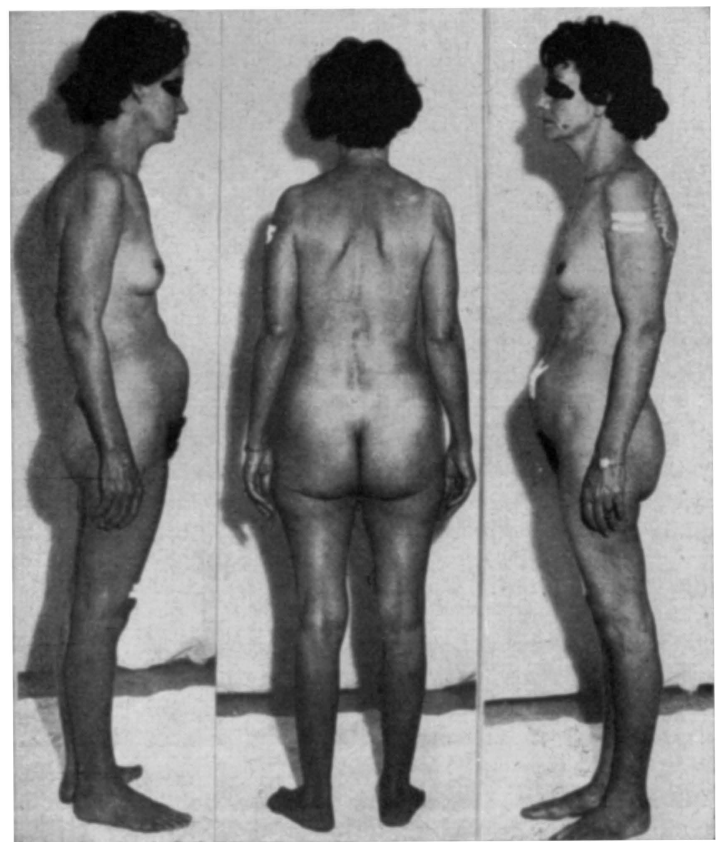

Fig. 3 - Caso 2, paciente IIIR12: atrofia pelvifemoral e escápulo-umeral. 
reoidectomia, tendo obtido beneficio parcial, persistindo até a presente data a intolerância ao calor, hipermotividade e "tremores". Em abril de 1957, ao levantar-se de uma banqueta, teria "embaraçado as pernas", tendo caído. Cêrca de 5-6 meses após (aos 46 anos de idade) notou diminuição de fôrça do membro inferior esquerdo, agravando-se progressivamente e perturbando a marcha. Após 4-5 meses, observou diminuição de fôrça de ambos os braços. Em início de 1960 surgiu "fraqueza" do membro inferior direito, tornando-se a marcha mais dificultosa, com quedas freqüentes. Ainda em inicio de 1960, notou "que as carnes tremiam, particularmente nos braços" e que os membros inferiores eram acometidos por caimbras muito dolorosas. Assinala que os tercos superiores das coxas começaram a diminuir de volume, com desaparecimento dos contornos. Nega distúrbios esfinctéricos. Em fevereiro de 1959, uma radiografia da coluna lombar mostrou "osteoporose acentuada". Radiografia da coluna dorso-lombar, em agôsto de 1960, evidenciou "espondilose da IV vértebra lombar e pinçamento da XII dorsal". Antecedentes pessoais: Parto eutócico, gestação a têrmo. Doenças peculiares à primeira infância isentas de complicações.

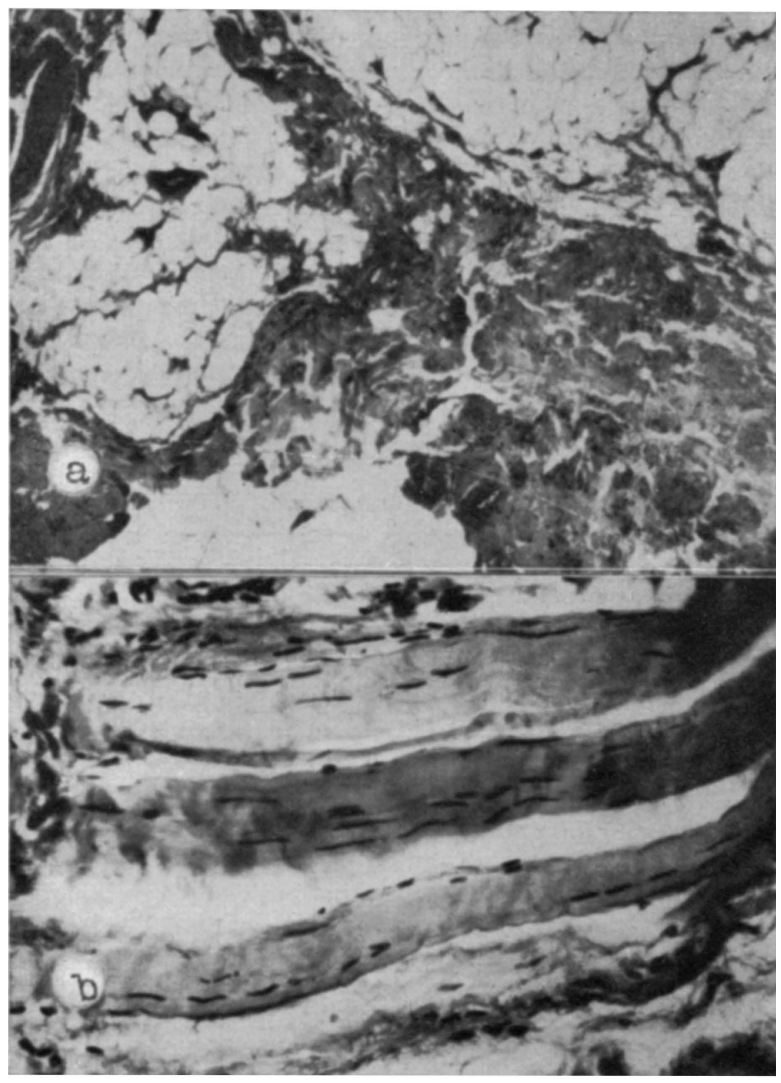

Fig. 4 - Caso 2, paciente IIIR12. Biopsia muscular: em a, predominio de tecido fibroadiposo com raros trechos de musculatura esquelética; em b, detalhe de fibra muscular estriada, com perda completa da estrutura miofibrilar (H.E. $100 \times$ e $240 \times$ ). 
Exame neurológico - Nistagmo fino, rápido, ùnicamente na mirada dianteira com oscilopsia. Demais nervos cranianos intatos. Tremor distal, fino, de ambos membros superiores na posiçāo de juramento. Marcha de palmipede. Marcha no: calcanhares possivel; marcha na ponta dos pés impossivel. Estática normal. Abdome protuberante com acentuação da lordose lombar. Atrofias dos glúteos, do tensor da fascia lata, de ambos biceps crurais, dos costureiros, adutores, vastos internos e externos; atrofia dos músculos da cintura escápulo-umeral (fig. 3). Diminuição da fôrça muscular de abdução dos ombros, de extensão dos antebraços, de abdução e adução dos membros inferiores, de flexão e extensão das coxas sôbre a bacia e de flexão das pernas sôbre as coxas. Não há reação miotônica. Levantar sugestivo de miopático. Aumento da passividade e diminuição da consistência muscular à palpação dos membros inferiores. Provas dedo-nariz e calcanhar-joelho normais. Reflexos musculares normais e simétricos. Sinal de Babinski bilateral. Fasciculações universalmente presentes, predominando nos braços e tórax. Sensibilidades superficial, profunda e discriminativa intatas. Psiquismo e linguagem sem alteraçōes.

Exames complementares - No sangue: uréia $20 \mathrm{mg} \%$; creatinina $1,7 \mathrm{mg} \%$; glicose $93 \mathrm{mg} \%$; colesterol total $200 \mathrm{mg} \%$; transaminase glutâmico-oxalacética $9 \mathrm{u}$./ $\mathrm{ml}$; transaminase glutâmico-pirúvica $61 \mathrm{u} . / \mathrm{ml}$. Captação de $\mathrm{I}^{131} 24,1 \%$ (normal 10 a $55 \%$ ); de $\mathrm{PBI}^{131} 0,087 \%$ L (normal 0,02 a $0,19 \%$ L). Biopsia muscular (material do têrço inferior da regiāo femoral direita e têrço superior da região deltoidiana esquerda): "Presença de tecido fibroadiposo, com escassos grupamentos de fibras musculares estriadas, cortadas ora longitudinal ora obllquamente. As fibras musculares estriadas exibem diâmetro reduzido, algumas inteiramente hialinizadas, outras com citoplasma homogêneo, pálido e sem estriação, embora com estrutura nuclear bem preservada. Ausência de infiltrados inflamatórios (fig. 4). Estruturas nervosas com arquitetura aparentemente normal. Artérias do tipo muscular, com moderado espessamento fibroso parietal" (Dr. Domingos De Paola).

CASo 3 - O.D.M. (IIIR11 no heredograma), 54 anos, branco, brasileiro (natural de Guarani, Minas Gerais), solteiro, examinado em 8-10-1960. História da doença atual - Relata o paciente que em meados de 1955 (aos 49 anos de idade) observou que cada vez que tentava erguer algum volume pesado do solo, os joelhos fletiam-se. Em seguida notou fatigabilidade fácil, diminuição de fôrça nos membros inferiores e fasciculações em todo o corpo. Simultâneamente dificuldade em elevar os membros superiores e inferiores. Recentemente dispnéia aos minimos esforços. Em meados de setembro de 1960, ocorreu episódio de agitação seguido de paralisia do braço e perna esquerdos, diagnosticado como "trombose cerebral". Antedentes pessoais - Alcoolismo crônico.

Exame neurológico - Nervos cranianos integros. Marcha só possivel com auxilio ou amparando-se em objetos. Lordose lombar pronunciada com cifose dorsal. Tremor distal de ambos membros superiores na posição de juramento. Atrofia pronunciada dos músculos da cintura escápulo-umeral, menor dos antebraços; acentuada dos músculos da cintura pelvifemoral e minima das massas gêmeo-soleares (fig. 5). Diminuição da fôrça de abdução e adução dos ombros, flexão e extensão dos antebraços e flexão da mão esquerda; fôrça de flexão das coxas sôbre a bacia quase abolida com preservação da fôrça de extensão das coxas, flexão e extensão das pernas, flexão e extensão dos pés. Não há reação miotônica. Hipotonia global. Reflexos musculares normais nos membros inferiores e abolidos nos superiores. Reflexos plantares em flexão. Fasciculações difusas, particularmente na parede anterior do tórax e braços. Sensibilidade integra a tôdas as modalidades, com exceção de hipoestesia superficial do dimidio esquerdo (seqüela de acidente vascular encefálico recente). 


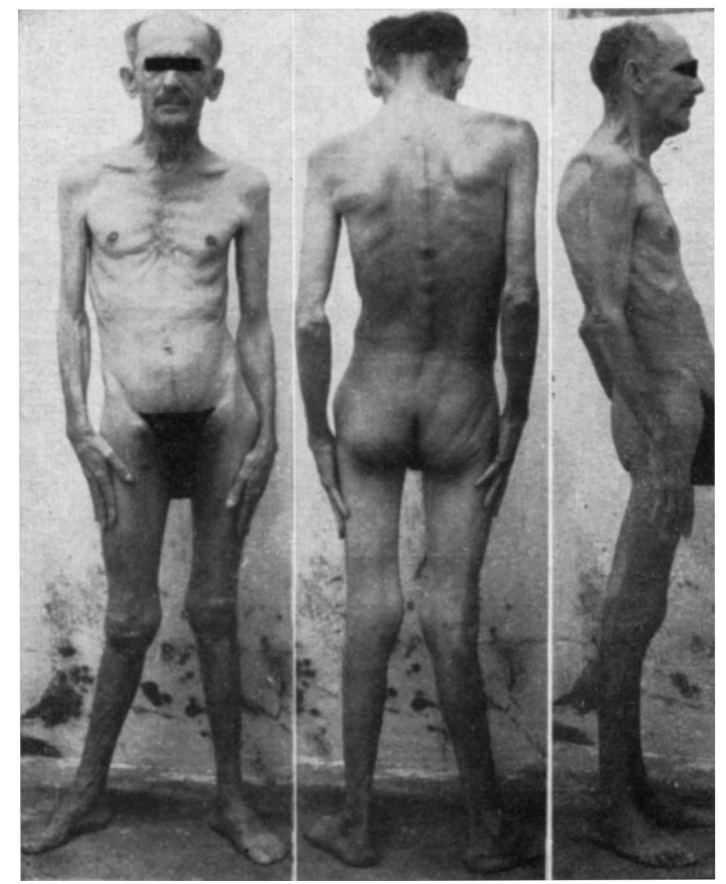

Fig. 5 - Caso 3, paciente IIIR11: atrofia pelvifemoral e escápulo-umeral.

CASo 4 - A.D.G. (IIID4 no heredograma), 69 anos, branca, brasileira (natural de Guarani, Minas Gerais), casada. Examinada em 8-10-1960. História da doença atual - Relata a paciente que desde meados de 1954 (aos 63 anos de idade) vem tendo dificuldades crescentes na marcha. Ulteriormente tornou-se "candenga igual aos parentes". Presentemente só consegue andar amparando-se nas paredes.

Exame neurológico - Nervos cranianos sem alterações. Marcha só possível com amparo, ensaiando marcha de palmipede. Estática normal. Lordose Iombar pronunciada. Abdome protuberante. Atrofia moderada, limitada aos músculos da cintura escápulo-umeral e pelvifemoral. Diminuiçāo pronunciada da fôrça de abdução do ombro direito e da flexão das coxas sôbre a bacia, moderada da flexão e extensão do antebraço sôbre o braço direito. Reflexos musculares diminuidos e simétricos nos membros superiores; patelares e aquileus presentes e simétricos; reflexos plantares em flexão. Fasciculações restritas à parede posterior do tórax. Tremor distal, moderado, de ambos membros superiores na posição de juramento. Sensibilidades superficial, profunda e discriminativa, intatas.

Análise genética da enfermidade - As informações colhidas para a confecção do heredograma foram obtidas de membros acometidos e não acometidos pela enfermidade em pauta, sendo que as datas de nascimento e falecimento de muitos individuos foram extraidas de documentos oficiais. Todos os informes foram várias vêzes cotejados entre aquêles que os forneceram. A análise genética (Dr. Virgílio Ferreira da Costa) originou a formulação que transcrevemos sumàriamente: 


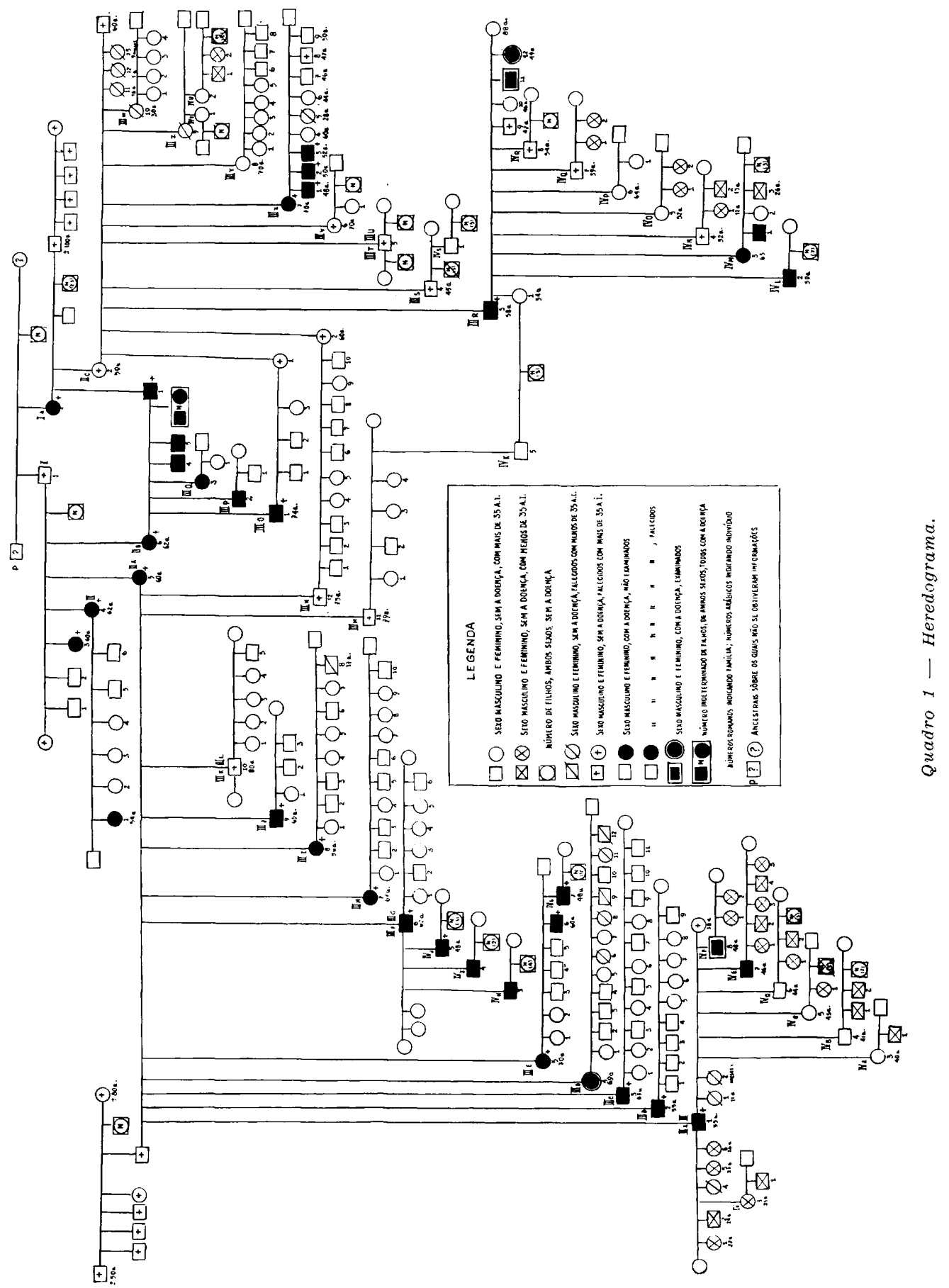


"A análise dos cruzamentos I e IIC (em que os pais são indenes mas têm filhos doentes) é incompativel com a hipótese de ser a enfermidade em causa determinada por fator dominante simples (monomérico), de vez que os pais, com o genótipo bi-recessivo, não poderiam transmitir o fator dominante, inexistente, a nenhum dos seus filhos. Todos os cruzamentos do diagrama, inclusive I e IIC, podem ser explicados admitindo a transmissão da doença como herança mendeliana determinada por fator recessivo simples, contanto que se torne concebivel uma das duas seguintes probabilidades: 1. que os portadores da gênia recessiva em causa sejam muito freqüentes, o que não parece corresponder à realidade, considerando-se a raridade da $€$ nfermidade em aprêço; 2. que tais "portadores" sejam, de algum modo, aparentados da família tronco na qual surgiu, pela primeira vez, a doença, o que poderia ser verdadeiro, de vez que se trata de velha familia do interior de Minas Gerais, de hábitos sedentários e patriarcais, onde os casamentos dos filhos se realizam sobretudo dentro da comunidade. Sendo, nessas familias, incomum a emigraçāo dos descendentes, torna-se infreqüente a seleção de parceiros entre membros de familias muito afastadas. Resta, não obstante, a possibilidade da interação de dois ou mais fatôres, dominantes ou recessivos, na determinação da afecção em tela. Nestas circunstâncias, um fator (ou mais de um) bastante difundido na humanidade poderia originar a doença, quando em interação com um outro (ou com outros) bastante raro, encontrado em certas familias.

Conclusões - 1) A doença estudada não seria determinada por fator dominante simples. 2) A enfermidade parece ser determinada por fator recessivo simples. 3) A análise do heredograma não exclui categoricamente a hipótese da interação de mais um fator na determinação da doença. A optar por uma das possibilidades acima arroladas, o estudo circunstanciado do heredograma favorece um tipo de heranca recessiva simples para a forma pseudomiopática tardia da atrofia muscular progressiva heredo-familia!".

\section{COMENTARIOS}

Em 1849 e 1850, Duchenne e Aran descreveram a atrofia muscular progressiva neurogênica, postulando errôneamente a sua origem muscular. Em 1869 Charcot e Joffroy descreveram a esclerose lateral amiotrófica, afirmando a gênese neurogênica da doença. Em 1875 Erb publicou trabalho sôbre "um complexo sintomático medular" que, desde então, figura sob a denominação de esclerose lateral primária. As três condiçōes acima arroladas fazem parte do grupo das "enfermidades do neurônio motor", no qual são incluídas também a doença de Werdnig-Hoffmann e a paralisia bulbar progressiva de Duchenne.

Fundamentando-se na similaridade das características anátomo-patológicas das doenças do neurônio motor, alguns autores adotam ponto de vista unicista ao afirmar que as mesmas constituem variantes de uma forma única, sendo a esclerose lateral amiotrófica a enfermidade paradigma. Marburg ${ }^{13}$ admite que as amiotrofias nucleares e a esclerose lateral amiotrófica constituem uma única entidade nosológica, distinguindo-se apenas quantitativa e não qualitatitativamente, admitindo também a possibilidade de formas de evolução lenta nas quais o bulbo e a via piramidal são acometidos tardiamente; opina Marburg pela inexistência das amiotrofias nucleares isoladas, afirmando que, ao exame histopatológico minucioso, sempre será evidenciada a degeneração da via piramidal. 
Quadros clínicos compativeis com o diagnóstico de atrofia muscular progressiva com localização proximal da atrofia e paresia, sem incidência heredo-familial foram descritos desde a segunda metade do século passado. Vulpian, em 1879, assinalou que, em determinados casos, a atrofia tem início pelos músculos dos braços e da cintura escapular. Para Vulpian, consoante a localização da lesão medular, ocorreriam duas formas clínicas diversas de atrofias musculares mielopáticas: a primeira, mais freqüente, começando distalmente nos membros superiores; a segunda, não de todo rara, incidindo inicialmente nos músculos da cintura escápulo-umeral (atualmente conhecida sob a denominação de tipo B de Vulpian-Bernhardt da atrofia muscular progressiva ou forma escápulo-umeral de Vulpian).

Em 1890, Spillman e Haushalter (cit. por Wohlfart 24) publicaram os casos de dois irmãos com atrofia proximal associada a fasciculações, que provàvelmente constituem exemplos da forma proximal da amiotrofia neurogênica progressiva hereditária, apesar de os autores opinarem pela sua inclusão no grupo das miopatias primitivas. Tratando da poliomielite anterior crônica, Dejerine e André-Thomas 5 referem a forma escápulo-umeral descrita por Vulpian e mencionam dois casos pessoais. No tocante à topografia da atrofia, observam que ela se assemelha ao "tipo escápulo-umeral da siringomielia e da miopatia atrófica progressiva". No mesmo livro, no capitulo devotado à esclerose lateral amiotrófica, Dejerine e André-Thomas assinalam que a atrofia pode começar pelos músculos proximais dos mœmbros superiores (tipo escápulo-umeral) e só ulteriormente são acometidos os extensores do punho e dedos, mais tarde os flexores e, por fim, todos os músculos da māo; reportam-se a duas observações pessoais desta modalidade, possivelmente as mesmas descritas no capítulo da poliomielite anterior crônica.

Sob o rótulo de "L'amyotrophie progressive spinale à debut et predominance proximaux: poliomyélite chronique pure", Louis-Bar ${ }^{11}$ relatou, em 1946, um caso que virtualmente se superpōe ao reportado por van Bogaert ${ }^{2}$ em 1930, de uma doente falecida aos 73 anos com história de amiotrofia difusa dos membros superiores, iniciada aos 68 anos, de predomínio proximal e associada a paresia de igual distribuição, com abolição dos reflexos musculares e raras fasciculaçōes. O exame histopatológico mostrou exclusivamente rarefação celular nas pontas anteriores da medula cérvico-dorso-lombar, particularmente cervical e dorsal superior.

Myrianthopoulos e Brown ${ }^{15}$, em 1954, publicaram um estudo genético da atrofia muscular progressiva, assinalando a indigência de informaçōes relativas ao tipo de herança decorrente da escassez, na literatura, de relatos dos antecedentes hereditários de portadores da enfermidade, se bem que os heredogramas por êles revistos indicassem herança dominante. Conceituam a atrofia muscular progressiva como doença resultante de lesão do neurônio motor, de etiologia desconhecida, expressando-se através das seguintes variedades: 1. forma espinal (tipo Aran-Duchenne e esclerose lateral amiotrófica); 2. paralisia bulbar progressiva; 3. oftalmoplegia externa progres- 
siva. Reportam êstes autores os heredogramas de dois pacientes, com o diagnóstico de atrofia muscular neurogênica progressiva, oriundos de duas famílias com numerosos membros, em várias gerações, portadores de variantes da enfermidade. Fundamentados no estudo dos dois heredogramas apresentados e da literatura pertinente, admitem a possibilidade de uma modalidade genética da atrofia muscular neurogênica progressiva, com capacidade de exteriorizar-se nas suas diversas variedades e que uma simples gênia dominante, com expressividade múltipla, poderia ser responsabilizada pela transmissão.

Wohlfart ${ }^{24}$, em 1942, sumarizando a literatura relativa aos quadros com feição clínica de distrofia muscular progressiva associados a fasciculações, adicionou duas observações pessoais nas quais biopsias musculares evidenciaram alterações interpretadas como distróficas (miogênicas) e neurogênicas (neurônio motor periférico). Kugelberg e Welander ${ }^{9}$ detectaram, pela eletromiografia, em um dos pacientes reportados por Wohlfart em 1942, modificações compativeis com lesão neurogênica. Estes últimos autores coligiram vários casos, com as características já assinaladas, opinando pela sua autonomia como doença hereditária. Welander ${ }^{22}$, em 1954, comunicou que, conjuntamente com Kugelberg, evidenciara alterações das pontas anteriores da medula em um caso necropsiado. Scheiffarth ${ }^{18}$, em 1954, relatou mais 3 casos sob o rótulo de "distrofia muscular com fibrilações".

Com as investigações epidemiológicas de Koerner 8 e de Mulder ${ }^{10}$ demonstrando a elevada incidência familial da forma clássica da esclerose lateral amiotrófica, a participação de fatôres genéticos passou a revestir-se de importância. Em quase tôdas as familias estudadas foram assinalados quadros clínicos de atrofia muscular progressiva e de paralisia bulbar progressiva, além da forma clássica da esclerose lateral amiotrófica.

Em 1955, Wohlfart e col. ${ }^{25}$ apresentaram 7 casos de 3 famílias diversas, discutindo o diagnóstico diferencial e mostrando que a eletromiografia perrnite estabelecer com segurança a origem neurogênica de certas atrofias musculares, constituindo sinal inequívoco a presença de potenciais de desnervação; o aumento da duração e amplitude médias dos potenciais de ação, a sincronização difusa ou a redução da atividade seriam igualmente importantes para o diagnóstico de atrofia neurogênica. Afirmam ainda que a biopsia muscular poderá fixar o diagnóstico de atrofia neurogênica (presença de fibras musculares atróficas em grupamentos típicos, grosseiramente nos mesmos estágios de atrofia e redução das fibras de maior diâmetro dos nervos intramusculares). Clìnicamente os casos 1, 2 e 7 relatados por Wohlfart e col. assemelham-se aos descritos por Wohlfart $\in m$ 1942. Em todos êstes casos existia atrofia muscular de localização proximal, associada a fasciculações. Nos casos descritos por Wohlfart em 1942, a histologia muscular evidenciou alterações do tipo distrófico. Lesões similares, porém mínimas, foram igualmente assinaladas no caso 5 da série apresentada por Wohlfart e col. em 1955. A presença de alterações histológicas com características distróficas em quadros clínicos sugestivos de atrofia neurogênica 
suscita de Wohlfart e col. a especulação causal de uma combinação de lesão neurogênica associada a miopatia primária. Adicionam, porém, que os achados do tipo distrofia nas biopsias musculares, também poderiam ser secundários a alterações primitivamente neurogênicas.

Até a presente data, a predileção da distrofia muscular progressiva para acometer grupos musculares proximais não teve explicação satisfatória. De acôrdo com Wohlfart ${ }^{24}$, assim como ocorre localização proximal ou distal nas miopatias, a atrofia muscular neurogênica hereditária poderia, também, exteriorizar-se por formas distais (amiotrofia de Charcot-Marie-Tooth) ou proximais.

Wohlfart discute a possivel relação entre os casos descritos e a atrofia muscular espinal infantil de Werdnig-Hoffmann ou a amiotonia congênita de Oppenheim. A forma hereditária da doença de Werdnig-Hoffmann constitui entidade diferenciada; contudo muitos casos têm sido publicados sob o rótulo de amiotonia congênita de Oppenheim. Krabbe assinala que os casos reportados como amiotonia congênita representam, na realidade, duas afecçōes diversas: uma, não familial, expressaria um atraso no desenvolvimento do sistema muscular, exteriorizando-se por hipotonia congênita, hiperextensibilidade e diminuição da fôrça muscular sem atrofia; a outra, se bem que congênita, poderia ser considerada como idêntica à doença de Werdnig-Hoffmann. Brandt 3 conclui pela inexistência de uma enfermidade que corresponda àquela descrita por Oppenheim sob o nome de amiotonia congênita, afirmando que os casos observados seriam, em sua quase totalidade, de doença de Werdnig-Hoffmann. Considerando que na doença de WerdnigHoffmann a atrofia e paresia têm predileção proximal e que em alguns de seus casos o início dos sintomas ocorreu na infância, Wohlfart não rejeita a possibilidade dos mesmos constituírem uma modalidade benigna daquela enfermidade (na realidade, van Bogaert ${ }^{2}$ define a atrofia muscular espinal infantil de Werdnig-Hoffmann, sob o ponto de vista anátomo-clínico, como uma atrofia muscular progressiva de Aran-Duchenne, sobrevindo na infância e ocasionalmente heredo-familial). Ao final do seu trabalho, Wohlfart e col. ${ }^{25}$ inclinam-se por considerar os casos relatados como representantes de uma enfermidade hereditária autônoma, genèticamente independente, òbviamente neurogênica a julgar pela presença de fasciculações e elementos fornecidos pela biopsia muscular e eletromiografia.

Kugelberg e Welander ${ }^{9}$ tiveram oportunidade de examinar 12 pacientes portadores de atrofia muscular hereditária do tipo juvenil, cuja natureza neurogênica foi confirmada pela biopsia muscular e eletromiografia. Os 12 pacientes pertenciam a 8 fratrias de 6 linhagens, não se verificando transmissão direta de pais para filhos, o que indicaria uma herança do tipo recessivo para a enfermidade. Desde que mais de um membro tinha sido acometido em quase tôdas as famílias analisadas, a doença pode ser considerada como hereditária e, consoante a pesquisa efetuada pelos autores, não ligada ao sexo. Consangüinidade entre os pais ocorreu apenas em uma família. A idade de início dos sintomas variava entre 2 e 17 anos (média 
de 9 anos). A biopsia muscular, feita em 5 doentes originários de linhagens diversas, mostrou alterações típicas da atrofia muscular secundária à degeneração dos neurônios das pontas anteriores da medula. A enfermidade tem curso lento, porém progressivo. Dois dos pacientes ficaram impossibilitados de andar 8 e 9 anos, respectivamente, após o início dos sintomas; sete deambulavam 20 anos após o advento da sintomatologia e, um, 40 anos após. Os autores assinalam que, não obstante os casos descritos assemelharem-se à distrofia muscular miopática, a presença de fasciculações, os resultados eletromiográficos e das biopsias musculares indicavam comprometimento do neurônio motor periférico. Por outro lado, Kugelberg e Welander observam que os seus casos, embora possam assemelhar-se à atrofia muscular espinal infantil de Werdnig-Hoffmann, apresentam peculiaridades permitindo de imediato a diferenciação.

Os 3 casos de "atrofia muscular neurogênica simulando distrofia muscular", relatados por Magee e DeJong 12, são muito semelhantes aos que tivemos oportunidade de examinar, distinguindo-se pelo início tardio (5. ${ }^{\mathrm{a}}$ década) e evolução para o êxito letal no prazo de 5 a 10 anos.

Hurwitz, Lapresle e Garcin ${ }^{7}$ fizeram revisão do problema em tela e apresentam dois casos esporádicos, sem incidência familial, nos quais a exteriorização clínica sugeria miopatia, mas os traçados eletromiográficos e as lesões histológicas musculares indicavam patologia neurogênica, mais precisamente de pontas anteriores da medula. Hurwitz e col. preconizam a utilização da eletromiografia e biopsia muscular, insistindo em sua contribuição decisiva na localização da lesão causal das síndromes neurológicas caracterizadas por diminuição de fôrça e atrofia com topografia proximal. Tais sindromes conduzem, de imediato, à formulação diagnóstica de miopatia, isto é, de processo degenerativo primàriamente muscular. Não obstante, lesões das pontas anteriores da medula, dos nervos periféricos ou miosites podem determinar sindromes pareto-amiotróficas de padrão superponível ao das distrofias musculares e, nestas circunstâncias, a eletromiografia e a biopsia muscular são de inestimável valia para o diagnóstico preciso. Consoante os autores, o problema inicial evocado pelos dois casos observados consistiu na catalogação nosológica, uma vez que êsses casos exibiam quadro clínico compativel com o diagnóstico de poliomielite anterior crônica; apesar da recusa de certos autores em emprestar autonomia à poliomielite anterior crônica, Hurwitz e col. a ela conferem independência, fundamentados nos estudos anátomo-patológicos de Lehoczky e col. e Alajouanine e col. O primeiro dos casos relatados por Hurwitz e col., pela evolução longa e presença de atrofia e fasciculações, foi identificado com o quadro clínico descrito por Vulpian como "forma escápulo-umeral da poliomielite anterior crônica"; o segundo caso, não fôsse o início aos 14 anos de idade e a progressão lenta, poderia ser rotulado como forma atípica da doença de Werdnig-Hoffmann.

De acôrdo com Hurwitz e col., uma sindrome neurológica constituída por atrofia de topografia proximal de início tardio, associada ou não a fas- 
ciculações, pode ser determinada por lesão degenerativa das pontas anteriores da medula, por miopatia ou miosite. Aduzem êstes autores, à guisa de corroboração do conceito emitido, a oportunidade de observância de um caso, embora não o relatem detalhadamente, exibindo atrofia proximal acompanhada de fasciculações, no qual a biopsia muscular teria mostrado alteraçōes de natureza distrófica; outro caso, mencionado pelos autores, diagnosticado como poliomiosite e confirmado por biopsia muscular, exibia fasciculações, sendo que meses após evolveu para um quadro de esclerose lateral amiotrófica. Assinalam ainda Hurwitz e col. a similaridade dos dois casos que observaram com aquêles descritos por Wohlfart e por Kugelberg e Welander, notando que, com tôda a probabilidade, a síndrome descrita por êstes últimos autores constitui uma entidade clinica e patológica definida e, sob o ponto de vista nosológico, uma forma de transição entre a atrofia espinal infantil e aquela de aparecimento tardio na idade adulta.

Pinelli ${ }^{16}$, em 1957, reportou dois casos de 5 e 9 anos de idade, respectivamente, com quadro de distrofia muscular progressiva, constituída por paresia e atrofia muscular difusa, com predileção inicial pelos segmentos proximais, diminuição dos reflexos musculares, ausência de fasciculações e decurso lento; o exame eletromiográfico, entretanto, sugeria "lesão crônica do neurônio motor periférico". Êstes dois casos foram considerados, inicialmente, como formas atípicas e tardias da doença de Werdnig-Hoffmann e, finalmente, rotulados como "poliomielite crônica do tipo Kugelberg e Welander". Ulteriormente, Pinelli ${ }^{17}$ cunhou a denominação "forma pseudomiopática da atrofia muscular progressiva infantil tardia de distribuição rizomélica e evolução benigna”, para designar aquêles casos.

Uma forma infantil tardia de evolução lenta da esclerose lateral amiotrófica foi descrita por Munch-Petersen ${ }^{14}$ como autônoma, caracterizada por início precoce, presença de alterações psíquicas e curso relativamente longo. A entidade reportada por Kugelberg e Welander distingue-se daquela individualizada por Munch-Petersen pela ausência de sinais piramidais, de disfagia e disartria e de distúrbios mentais.

Ford ${ }^{6}$ descreve um tipo de atrofia muscular espinal juvenil que, a seu ver, estaria mais próximo do padrão da esclerose lateral amiotrófica do que o da enfermidade de Werdnig-Hoffmann, caracterizando-se pelo início aos 5-15 anos de idade, evolução rápida e comprometimento da musculatura bulbar associado a distúrbios psíqulcos.

\section{RESUMO}

Sob o rótulo de "forma pseudomiopática tardia da atrofia muscular progressiva heredo-familial" são relatados 4 casos exibindo características clínico-evolutivas similares. A análise genética levou a admitir, para a enfermidade, um tipo de herança recessiva simples. 
SUMMARY

Late pseudomyopathic form of progressive heredofamilial muscular atrophy.

Under this title four cases showing similar clinical and evolutive features are reported. The genetic study of the available pedigree favors a simple recessive type of inheritance for the disease.

\section{REFERENCIAS}

1. BOGAERT, L. van - Forme proximale de l'amyotrophie spinale. J. Belge Neurol. et Psychiat., 30:514, 1930. 2. BOGAERT, L. van - Les maladies systématisées. In Traité de Médicine. Vol. 16. Les Maladies du Système Nerveux. Masson et Cie., Paris, 1949. 3. BRANDT, s. - Course and symptoms of progressive infantile muscular atrophy. Arch. Neurol. a. Psychiat., 63:218, 1950. 4. CURSCHMANN, H. - In Bumke, O. e Foerster, O. - Handbuch der Neurologie, vol. 17, Julius Springer, Berlim, 1936. 5. DEJERINE, J.; ANDRE-THOMAS - Maladies de la mœlle épinière (XXXIV). J. B. Ballière et Fils, Paris, 1909, págs. 504-505 e 528. 6. FORD, F. R. - Diseases of the Nervous System in Infancy, Childhood and Adolescence. 3rd edition, Charles C. Thomas, Springfield (Illinois), 1952, págs. 404-409. 7. HURWITZ, S.; LEPRESLE, J.; GARCIN, R. - Atrophie musculaire neurogène de topographie proximale et symétrique simulant une myopathie. Rev. Neurol., 104:97, 1961. 8. KOERNER, D. R. - Amyotrophic lateral sclerosis on Guam: a clinical study and review of the literature. Ann. Int. Med., 37:1204, 1952. 9. KUGELBERG, E.; WELANDER, L. - Heredofamilial juvenile muscular atrophy simulating muscular dystrophy. A.M.A. Arch. Neurol. a. Psychiat., 75:500, 1956. 10. KURLAND, L. T.; MULDER, D. W. - Epidemiologic investigations of amyotrophic lateral sclerosis: familial aggregations indicative of dominant inheritance. Neurology, 5:182196 e 249-268, 1955. 11. LOUIS-BAR, D. - L'amyotrophie progressive spinale à debut et predominance proximaux: poliomyelite chronique pure. J. Belge Neurol. et Psychiat., 44:432, 1946. 12. MAGEE, K. R.; DeJONG, R. N. - Neurogenic muscular atrophy simulating muscular distrophy. A.M.A. Arch. Neurol., 2:677, 1960. 13. MARBURG, O. - Die chronischen progressiven nuclearen Amyotrophien. Die amyotrophische Lateralsklerose. In Bumke, O. e Foerster, O. - Handbuch der Neurologie, vols. 6 e 7. Julius Springer, Berlim, 1936. 14. MUNCH-PETERSEN, C. J. - Studien über Erbliche Erkrankungen des Zentralnervensystems: die familiäre amyotrophische Lateralsklerose. Acta Psychiat. et Neurol. Scandinavica, 6: 55, 1931. 15. MYRIANTHOPOULOS, N. C.; BROWN, I. A. - A genetic study of progressive spinal muscular atrophy. Am. J. Human Genet., 6:387, 1954. 16. PINELLI, P. - Sul disturbo fondamentale della miastenia e sulle sindromi e disturbi miasteniformi. Riv. de Pat. Nerv, e Ment., 78:121, 1957. 17. PINELLI, P. - Su di una forma pseudomiopatica: l'atrofia muscolare progressiva tardo-infantile a distribuzione rízomelica e decorso benigno. XIII Congresso Società Italiana di Neurologia, Messina, 7-10 Maggio, 1959. 18. SCHEIFFARTH, H. - Morphologische Untersuchungen bei der Dystrophia musculorum progressiva mit fibrillären Zuckungen. Comunicação à Deutschen Gesellschaft für Neurologie, Würzburg, 1954. 19. SPILLER, W. G. - The relation of the myopathies. Brain, 36:75, 1913-14. 20. VULPIAN, A. - Cours de Pathologie Expérimentale. Maladies du Système Nerveux (Moelle Épinière). Tome II. Octave Doin, Paris, 1879, pág. 436. 21. WELANDER, L. Neostigmine as a diagnostic test in progressive muscular atrophy and dystrophy. Acta Psychiat. et Neurol. Scandinavica, supl. 46, 1947. 22. WELANDER, L. - 
Discussão em sessão da Deutschen Gesellschaften für Neurologie, Würzburg, 1954. 23. WOHLFART, G. - Zwei Fälle von Dystrophia musculorum progressiva mit fibrillären Zuckungen und atypischen Muskelbefund. Ein Beitrag zur Frage des Vorkommens von Ubergangsformen zwischen progressiver Muskeldystrophie und neuraler progressiver Muskelatrophie. Dtsch. Ztschr. f. Nervenh., 153:189, 1942. 24. WOHLFART, G. - Muscular atrophy in diseases of lower motor neuron. Arch. Neurol. a. Psychiat., 61:599, 1949. 25. WOHLFART, G.; FEX, J.; ELIASSON, S. - Hereditary proximal spinal muscular atrophy: a clinical entity simulating progressive muscular distrophy. Acta Psychiat. et Neurol. Scandinavica, 30:395, 1955.

Avenida Rio Branco, 185, sala 141 - Rio de Janeiro, Guanabara - Brasil. 